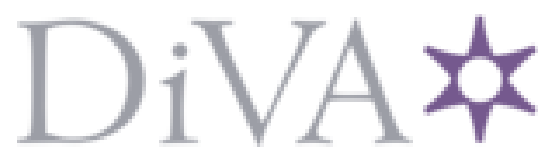

http://www.diva-portal.org

\title{
Preprint
}

This is the submitted version of a paper published in Journal of Marriage and Family.

Citation for the original published paper (version of record):

Trifan, T., Stattin, H., Tilton-Weaver, L. (2014)

Have authoritarian parenting practices and roles changed in the last 50 years?

Journal of Marriage and Family, 76(4): 744-761

http://dx.doi.org/DOI: 10.1111/jomf.12124

Access to the published version may require subscription.

N.B. When citing this work, cite the original published paper.

Permanent link to this version:

http://urn.kb.se/resolve?urn=urn:nbn:se:oru:diva-38574 


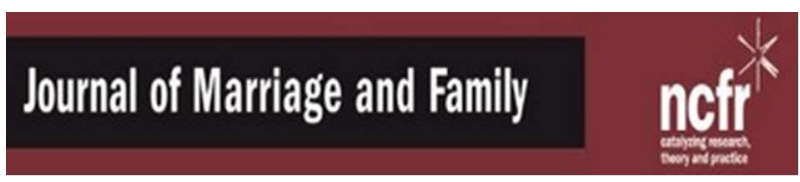

\section{Have Authoritarian Parenting Practices and Roles Changed in The Last Fifty Years?}

\begin{tabular}{|r|l|}
\hline Journal: & Journal of Marriage and Family \\
\hline Manuscript ID: & JMF-2013-3545-MS.R1 \\
\hline Manuscript Type: & Original Manuscript \\
\hline Keywords: & $\begin{array}{l}\text { Parenting < Parenting and Parenthood, Parent-child relations < Parenting } \\
\text { < Parenting and Parenthood, Family roles < Gender, Cohort < Social } \\
\text { Context, Child discipline/guidance < Parenting < Parenting and Parenthood }\end{array}$ \\
\hline \multicolumn{2}{|l}{} \\
\hline
\end{tabular}




\section{Have Authoritarian Parenting Practices and Roles Changed in The Last Fifty Years?}




\begin{abstract}
This study examined changes in authoritarian parenting practices and family roles in Sweden over the last 50 years. Data came from three cohorts $(1958,1981$, and 2011) of young to middle adults living in a suburb of Stockholm who answered questions about how they were raised $\left(N_{1958}=385, N_{1981}=207, N_{2011}=457\right)$. Results showed a dramatic decrease in parents' directive control. Also, over time, parents increasingly allowed children to express anger toward them. Parents' roles changed from stereotyped versions of fathers as decision-makers and mothers as caregivers to both parents sharing decisions and garnering respect from children. Overall, results suggest that authoritarian parenting practices have declined dramatically and moved towards more egalitarian family environments. These changes in parental practices and parental roles were more pronounced between the last two cohorts.
\end{abstract}

Keywords: child discipline/ guidance; cohort; gender; family roles; parent-child relations; parenting 
Have Authoritarian Parenting Practices Declined in The Last Fifty Years?

Western societies have been changing rapidly over the last 50 years. The social and economic conditions for families today differ substantially from the conditions of families living several decades ago. Also, social policies about families have changed. The question is whether there has also been a clear trend in the way parents raise their children. Is parenting today fundamentally different from what it was some generations ago? In this study, we focus on parenting practices typically associated with authoritarian parenting, such as directiveness (Robinson, Mandleco, Olsen, \& Hart, 1995); harsh parenting practices (Amato \& Fowler, 2002); strictness, punitiveness, and constraining the expression of negative emotion (Schaefer \& Bell 1958). We also look at how parental roles associated with authoritarian ideals have changed. In this study we examine how these aspects of authoritarian parenting have changed over the last 50 years.

Authoritarian parenting was the first parenting style to be described. The first systematic studies on authoritarian parenting date from the late 1940s (e.g. Baldwin, 1948), whereas references to other parenting styles started to appear at least a decade later (Baumrind, 1966). It is also the type of parenting most likely to have changed in the last 50 years, because the practices associated with authoritarian parenting style reflect, at the family level, a traditional hierarchical structure common to many societies during the first half of the $20^{\text {th }}$ century. That is, in hierarchical structures people in positions of authority expect obedience and unquestioning acceptance of their authority (see Durrant, Rose-Krasnor, \& Broberg, 2003, Gadlin, 1978). Disobedience is met with punishment. During the latter half of the $20^{\text {th }}$ century, western societies started changing from hierarchical organization toward more egalitarian structures (see Oppenheimer, 2004). In keeping with studies showing that harsh parenting practices have 
negative effects on children's development (e.g., Baumrind, 1966; Straus \& Paschall, 2009), many authoritiarian practices are now regulated. For example, the use of corporal punishment is banned in some countries (United Nations, 2011). These developments towards egalitarianism in society and acknowledgement of children's rights make it plausible that parents' use of practices associated with the authoritarian parenting style have also changed. With more than 70 years of research examining their effects on child development and legislation regulating some of these practices, the authoritarian parenting practices based on control are ideal candidates for studying parenting trends in the second half of the $20^{\text {th }}$ century.

In light of how parenting is embedded in culture and time, it is surprising that changes in parenting have not been the subject of much research. There are few studies focusing on changes in parenting practices over time. Those that exist suggest that there have been improvements in parenting and family life over time. For example, middle-aged adults born in Britain in 1958 felt emotionally closer to their parents than those born in 1946 (Ferri \& Smith, 2003). Similarly, adolescents in a 2006 UK cohort reported that their parents showed more interest in them, were more inclined to listen to their ideas, and spent more time with them than adolescents from a 1986 cohort (Nuffield Foundation, 2009; Scott, Collishaw, Gardner, \& Maughan, 2009). This evidence suggests that parenting practices have become more child-centered. Still, the evidence covers less than three decades and involves rather positive parenting practices (i.e., affection, interest, time spent together). Further, the use of positive parenting practices does not negate the use of strict, punitive parenting practices, as they are two separate constructs (e.g., Amato \& Fowler, 2002). Thus, the aforementioned studies do not address whether harsh parenting associated with the authoritarian style has declined.

Research on intergenerational transmission of parenting also offers information about 
changes in parenting practices. Intergenerational studies suggest that there have been shifts away from authoritarianism over generations in the same families. For example, in a study of two generations of Australians, parents in the second generation perceived themselves as less authoritarian than their parents (Campbell \& Gilmore, 2007). In a generational comparison of Korean fathers, Jung and Sterling Honig (2000) found shifts toward more democratic parenting. In line with these declines in authoritarian parenting, a study of two generations in the US found that both men and women from the younger generation reported more positive feelings toward their children than their parents did (Thornberry, Freeman-Gallant, Lizotte, Krohn, \& Smith, 2003). Overall, these studies suggest that the use of authoritarian parenting practices has decreased with successive generations. Nevertheless, this is only indirect evidence of how authoritarian parenting might have changed within the greater community. That is, changes associated with generational transmissions within families do not mean that mean-level changes between families have occurred (see Bronfenbrenner, 1986; Straus, 2010). Further, family members share an environment and have a common genetic background. The shared features between parents and children often mean that the estimates of parenting over generations within families are more stable than estimates of change within the larger population. There are also other methodological limitations that limit generalizability. The most evident issues are small sample sizes (Jung \& Sterling Honig, 2000), the use of clinical samples (Thornberry et al., 2003), and the use of single reporters for information on both generations (Campbell \& Gilmore, 2007). The above-mentioned studies, then, provide evidence of a shift away from authoritarianism within the family over generations, but these findings cannot be generalized to the societal level. The comparison of the frequency of harsh disciplinary practices over time provides more direct evidence about historical trends in authoritarian parenting, because research has associated 
these practices with an authoritarian parenting style (e.g., Baumrind, 1966; Brenner \& Fox, 1999; Robinson et al., 1995). Many studies on parents' disciplinary practices have focused on physical punishment, one of the hallmarks of authoritarian parenting (e.g., Baumrind, 1991; Conrade \& Ho, 2001; Russell, Aloa, Feder, Glover, Miller, \& Palmer, 1998). Research examining cohort differences suggests that in many countries the attractiveness of physical punishment has waned (Bussmann, Erthal, \& Schroth, in press; Zolotor, Theodore, Runyan, Chang, \& Laskey, 2011). In Sweden, where the first laws banning physical punishment were enacted, the use of physical punishment appears to have declined (Durrant et al., 2003). Studies examining parenting in the 1950 s and the ' 60 s reported that at least a third of parents used more severe forms of physical punishment, such as beatings (Stattin, Janson, Klackenberg-Larsson, \& Magnusson, 1995). This percentage has been considerably lower in more recent research (e. g., under 5\% in 2007; Bussman et al., in press). Rates of physical punishment have also dropped in countries where there has been no legislation banning its use (Bussman et al., in press; Straus, 2010). In light of these findings, it seems that parents' use of physical punishment, one of the characteristics of the control dimension in authoritarian parenting, has become less frequent over the last fifty years. Although these studies offer a clear view of changes in the use of physical punishment, they are limited to only one type of authoritarian parenting practices, and do not show whether there are changes in the other trademark features of authoritarian parenting.

Taken together, existing research offers little direct evidence of how parenting practices based on directive control have changed over time, and the picture is not entirely conclusive due to methodological problems. Even in cohort studies, which provide direct evidence of changes in the use of authoritarian practices, the information is limited to rates of physical punishment (e.g., Durrant et al., 2003; Straus, 2010), requiring an inference that other features of 
authoritarian parenting practices have declined as well. No study, to our knowledge, has explicitly focused on trends in authoritarian parenting practices, using the same measures over time, and assessing a range of authoritarian practices over longer periods of time. Answering this question is important, because it can help us understand the temporal changes in parenting practices, which might raise further questions about the role of society and laws in shaping them.

A thorough analysis of the changes in authoritarian practices cannot be completed without taking into account the changes in the distribution of parental roles in the family. The two concepts, parental practices and parental roles, are both influenced by societal norms and laws. Both contribute to children's adjustment (e.g., Baumrind, 1966; Strauss \& Paschall, 2009; Hofferth \& Goldscheider, 2010). An authoritarian parenting style is expected in a more traditional family (see Durant et al., 2003, Gadlin, 1978), where the roles are more rigid than in more democratic families. The two concepts are connected and researchers have raised the issue of changing roles to explain changes in parenting (e.g., Hofferth \& Goldscheider, 2010; Sarkadi, Kristiansson, Oberklaid \& Bremberg, 2008). No research, to our knowledge, has directly examined changes in both parental roles and parental practices in the same family. Having a clear idea of what changes, parental practices or parental roles, is important for understanding the influence of society and laws over family life.

To fill these gaps, we examined how authoritarian parenting practices and parental roles have changed over the last 50 years in Sweden. We used the hallmark practices of the control dimension of the authoritarian parenting style, because its outcomes have been amply researched and its practices have been subjected to legal and societal regulations. Moreover, in the last few decades there has been an increasing emphasis on egalitarianism and democratizing the institutions throughout European societies. Therefore, it is reasonable to think that such trends 
towards egalitarianism and democracy might also be reflected at the family level. It is also reasonable to think the trend toward egalitarianism and democracy might have influenced family roles, challenging the traditional authority of the father specific to hierarchical societies. In our study, we used retrospective reports from adults in the same community who were assessed as three cohorts: a 1958 cohort, a 1981 cohort, and a 2011 cohort.

In addition to examining adults' perceptions of their parents' use of authoritarian practices and the distribution of parental roles in the family, we also explored the ways in which participants' gender shaped these perceptions. Most of the studies of parenting styles and practices, especially those that have focused on the ways parents discipline children, have shown that parenting differs as a function of both parents' and children's gender (Russel et al., 1998, Conrade \& Ho, 2001, Stattin et al., 1995). Traditionally, mothers and fathers' roles reflected different aspects of authoritarianism, with fathers making decisions, directing the family, and requiring obedience and respect of the child, and mothers providing children with nurturance and support, but delegating punishment to fathers (Hosley \& Montemayor, 1997; Michael, 1987; Nelson, Padilla-Walker, Christensen, Evans, \& Carroll, 2011; Russell et al., 1998). Indeed, in past research, children and adults have perceived fathers as more authoritarian than mothers (Campbell \& Gilmore, 2007, Conrade \& Ho, 2001, Hosley \& Montemayor, 1997, Lewis, 1981; Russell et al., 1998). With respect to gender differences in children's experiences of authoritarian parenting, sons have reportedly been more likely to be the targets of authoritarian practices than girls (Conrade \& Ho, 2001; Nelson et al., 2011; Russell et al., 1998). If authoritarian parenting has really changed, we should also see changes in the gender-stereotyped parenting roles and gender-typed discipline practices as well. Thus, we examined gender issues in authoritarian parenting both in terms of parents' roles and in parenting boys versus girls. 


\section{METHOD}

\section{Participants}

The present study examined three cohorts of adults living in Solna, a suburb of Stockholm, Sweden. They were assessed in 1958, 1981, and 2011, respectively. The first two cohorts were part of a longitudinal study, the Solna Study, which started in 1955 at the Clinic for the Study of Children's Development and Health at the Karolinska Hospital, Stockholm. The goal of the original study was to map the physical and mental development of children in a normative sample (see Karlberg, Klackenberg, Klackenberg-Larsson, Lichtenstein, Stensson, \& Svennberg, 1968). Researchers asked every fourth pregnant woman who visited the prenatal clinic in Solna for routine checkups between December 1955 and April 1958 whether they wished to participate in a long-term study. Only 3\% of the women refused. A pilot group of 29 mothers and their children selected from private obstetricians clientele was added (Karlberg et al., 1968). The total sample included in the study was 212 children (122 boys and 90 girls) and their parents. The sample was representative for the Stockholm area. A more detailed description of the sample can be found elsewhere (Klackenberg, Karlberg, Klackenberg-Larsson, Lichtenstein, Stensson \& Svennberg, 1968). In Sweden all pregnant women, irrespective of their socio-economic background, are granted free routine checks to specialists. Most of the births in $1958(98.5 \%)$ took place in a hospital (Statistics Sweden, 1960).

The first cohort (labeled the 1958 cohort) consisted of the parents of the 212 children who participated in the longitudinal Solna Study. When their children were three or four years old, 385 of these parents participated in the data collection used in this study. The sample of parents included 202 women ( $M$ age 30.25 years) and 183 men ( $M$ age 34.15 years). Most participants (93.2\%) were born in Sweden, with the remainder being born in other Nordic 
countries. When the children were three years old, $91 \%$ of the couples were married. About $98 \%$ of the men and $19.3 \%$ of the women were employed full-time during the first three years of their children's lives. All participants had finished at least compulsory basic school, and 22\% of the men and $14 \%$ of the women had attended university. For most of the women, this was their first child (41.6\%) or second (44.6\%). The taxable income and the socioeconomic status of the participants in this cohort were close to the average of the Swedish population in general (Karlberg et al., 1968) and similar to the distribution of socio-economic conditions within the Stockholm area (see Karlberg et al., 1968; Klackenberg, 1968). In short, our first cohort consisted of 385 middle-class adults, almost all of Swedish origin, who answered questions about their own upbringing when their children reached age three or four.

The second cohort (labeled the 1981 cohort) included the children of the 1958 cohort. When they were 25 years old, they answered the same questions their parents had answered 23 years earlier. Of the 212 children recruited in 1958, almost 98\% $(n=207 ; 121$ men and 86 women) still lived in Sweden in 1981 and consented to participate. From this sample, 151 participants (87 men and 65 women) answered the questions regarding their parents' practices. By this time, all of them had finished middle school, $80 \%$ had finished high school, and 22\% had finished at least one semester of university studies. Almost a quarter, $25.4 \%$, of the participants had children at the time of data collection. For $75 \%$ of them, this was their first child. Almost $80 \%$ of the young adults were working full-time, with the remaining $20 \%$ still studying.

The third cohort, labeled the 2011 cohort, was comprised of 457 parents identified by Statistics Sweden as living in Solna and having three-year-old children. Questionnaires were sent to the parents by mail. Sixty percent of the target sample $(N=606)$ filled out the questionnaires and sent them back. From the completed questionnaires, we selected participants 
who were born in Sweden or other Nordic countries $(N=457)$. We considered this selection necessary to make accurate comparisons with the previous two cohorts, where all were born in Sweden or in other Nordic countries. The average age for the selected sample was 35.40 years for women and 38.02 years for men. More than half of the participants (59.7\%) were married and $32.4 \%$ were cohabiting. Fewer than $2 \%$ of the people were single parents with sole custody. For more than half of the participants (62\%), the child in the study was their second child and for $24 \%$ of them this was their first child. The education level, the household income, and the unemployment of this sample were about the same as for the Stockholm area as a whole (Statistics Sweden, 2010). Participants in this cohort were slightly better educated and had higher incomes than the general population of Sweden. With only one exception, all the people in this cohort had finished high school and more than half of them (53.8\%) had more than three years of college or university. Almost $88 \%$ of the participants had household incomes above the Swedish average household income in 2010 (about 29,000 - 38,000 Swedish Crowns per month according to Statistics Sweden), with more than half of them reporting household incomes of more than 50,000 Crowns per month. Only $3 \%$ of the participants lived in households in which the main income source was unemployment benefits. According to Statistics Sweden, the unemployment rate for this area in 2010 was lower than the national level of $8.4 \%$, but at the same level (7.1\%) as the Stockholm area.

\section{Procedures}

The participants from the first two cohorts were from the longitudinal Solna Study. The men and women from the first cohort answered questionnaires at the clinic when their children were three or four years of age; their children, the 1981 cohort, answered the questions at the clinic when they reached age 25 . The participants in the 2011 cohort responded to questionnaires 
sent to them by mail. For the first two cohorts, the incentives were travel expenses to the clinic and a printed photograph of the child taken by the investigators at each measurement to monitor the physical growth of the children (Karlberg et al., 1968). For the last cohort, the incentive was a certificate for groceries worth 250 Swedish Crowns $(\approx \$ 36)$.

Measures

We used two groups of measures to capture authoritarian practices: parents' use of directive control and the distribution of parental roles in the family. Concerning the first group of measures, we focused not on the parental style in itself, but on parental practices associated with it, because parenting practices are more sensitive to social influence (Darling \& Steinberg, 1993). Authoritarian parents expect unquestioning obedience from their children, offer clear rules, and tend to punish children harshly when they disobey (Baumrind, 1991; Maccoby \& Martin, 1983).

Directive control. Directive control was measured with questions tapping four control practices most frequently encountered in the literature on authoritarian parenting: demanding obedience, physical punishment, restricting children's expressions of anger, and strictness.

Demanding obedience. We measured demanding obedience with the question "Did your mother/father/parents always demand obedience from you?" with two response options: yes (at least one of the parents always demanded obedience) and not always. This question was asked for "parents" in the 1958 and 2011 cohorts, but asked separately for mothers and fathers in the 1981 cohort. To equalize the measures, the responses in 1981 were recoded to match those of the other cohorts: the value two was assigned if one or both parents always demanded obedience from their children, and one was assigned when neither parent always required obedience.

Physical punishment. As an indicator of physical punishment, we used the question: 
“Were you slapped as a child?” The responses for this question were never (1), rarely (2), or often (3). Because this item was asked separately for mothers and fathers in the 1981 cohort, we also recoded these responses. For the first and last cohorts, the value one was assigned to the responses never and rarely, whereas the value two was assigned to often. For the 1981 cohort, the value two, meaning often was assigned if one or both of the parents slapped often. All other combinations were assigned the value of one. Thus, the responses were recoded such that participants who reported being slapped often by one or both parents were assigned value two and all other reports were assigned value one.

Restricting children's expressions of anger. One retrospective item was used. "Were you allowed to show anger toward your parents" gauged whether participants' angry responses were restricted during childhood. Participants answered yes (1) or no (2).

Strictness. One item, "How strict was your father [mother]," tapped fathers' and mothers' strictness, with response options ranging from very strict (strict requirements of obedience and behavior) (5) to quite mild, without punishments or harsh demands (1). This item was available only for the last two cohorts and was asked separately for mothers and fathers.

The distribution of roles in the family. To capture potential shifts over time toward more democratic approaches of family roles, we used three questions. The participants were asked: "Who made decisions at home," "Who did you respect most," and "Who did you turn to the most?" For the first two questions, participants could indicate that either the mother alone (1), father alone (2), or both (3) made decisions and were respected by them during childhood. For the last question, participants were given three options: mother only (1), father only (2), or both (3) were the person(s) they turned to for support.

The validities of these retrospective measures were established in a previous study 
(Stattin et al., 1995), in which the second cohort's retrospective reports of parental discipline were compared with the first cohort's (i.e., their parents') prospective reports. The results showed significant associations over time between parental reports of disciplinary practices at different ages of their child (from 6 months until age 16) and child's retrospective reports during young adulthood (Stattin et al., 1995). The associations ranged between .18 and .54, with higher correlation coefficients for reports on parental use of physical punishment in early adolescence for both genders. The associations remained significant irrespective of the child's gender and irrespective of the distance in time between parents' and children's reports (Stattin et al., 1995).

Socio-demographic measures. The young adults reported their ages and education levels for 1958, 1981 and 2011 cohorts. They also reported information regarding their socioeconomic status for both 1958 and 2011 cohorts. The latter was calculated using the Graffar scale for the 1958 cohort (see Karlberg et al., 1968) and by creating a SES index from the available data on income, education, economic strains, and dwelling, for the 2011 cohort. The Graffar scale is an extended measure of socio-economic class, and includes five criteria: occupation, education, income, dwelling, and type of neighborhood (see Graffar \& Corbier, 1972; Klackenberg et al., 1968). Each criterion is evaluated on a 5-point scale, and a total score is computed. Higher SES index scores, or Graffar scale scores indicate higher socio-economic status.

\section{Data Analysis}

Binomial logistic, ordinary least squares regression (OLS), and multinomial logistic regressions were used to examine cohort and gender differences in directive control and distribution of roles in the family. We used hierarchical models, first testing for cohort effects, followed by gender differences, with a final step including the interaction between cohort and gender. To examine changes in parenting and parental roles across all three cohorts, we followed 
the recommendations for examining more than g-1 comparisons (Cohen \& Cohen, 1983: Pedhazur, 1997). Specifically, we effect-coded cohort, where the 1958 cohort served as a baseline (assigned -1 for both coded vectors) and the 1981 and 2011 cohorts were the alternatives (alternating assignment of 1 and 0 in the two coded vectors). According to Pedhazur (1997), the procedures for testing more than g-1 differences require this coding and a significant omnibus test (e.g., $\mathrm{F}$ test or $\chi^{2}$ test for the combination of effect codes), signifying the presence of at least one significant difference. When there is a significant omnibus $\mathrm{F}$ test or $\chi^{2}$, probing can then be accomplished with a variety of comparisons. We were interested in only three comparisons: the first to the second and last cohorts, and the second to the last cohort. To probe these differences we used two sets of dummy coded vectors. The first set compared the 1958 cohort (assigned 0) to the 1981 and 2011 cohorts (alternating assignment of 1 and 0 ). The second set compared the 1981 cohort to the 2011 and 1958 cohorts. Although the second coded vector in this set is needed to complete the g-1 codes, it is redundant with the first set of comparisons, so it was not reported. To adjust for the inflation of Type I error created by the post-hoc testing, we used a Bonferonni adjustment, setting the alpha level at 0.0167 . Men were the comparison group for gender. We probed interactions by separately analyzing gender differences in each cohort. For expressing the likelihood of change in parenting practices and parental roles, we used the $\operatorname{Exp}(B)$, the exponential regression coefficient or the Odds Ratio. We controlled for age and education in all our analyses.

Missing data varied between .02 and 11.4 percent in the 1958 cohort, between 0.01 and 4.5 percent in the 1981 cohort, and between .02 and 3.72 percent in the 2011 cohort. We created dummy codes for each of the study variables, indicating missingness, and regressed this type of data collection, age, and gender on these dummy codes. After correcting the alpha for multiple 
tests, only one significant difference emerged: the participants filling out questionnaires at the clinic had more missingness on the question about which parent they turned to when distressed than those filling out questionnaires at home.

\section{RESULTS}

Before analyzing the changes in harsh parenting and parental roles over time, we looked at how the socio-demographic aspects were associated with our measures in each cohort. Table 1 shows the correlations between our measures of authoritarian control and the socio-demographic variables, and the mean differences in socio-demographics for parental roles. Due to the very low variance in age and socio-economic status in the 1981 cohort, we decided not to include the associations between the socio-demographic measures and the directive control measures in our results. The correlations and the mean differences were computed separately for the 1958 and 2011 cohorts. We calculated only the cross-sectional correlations and mean-differences, because changes over time in income and socio-economic status make comparisons across cohorts difficult to interpret. In the 1958 cohort, age was positively associated with parents demanding obedience, and the father making household decisions. In the 2011 cohort, age was positively associated with maternal and paternal strictness. Higher education was only associated with both parents being viewed as the main supporter in the 2011 cohort, rather than mother only. High social class in the 1958 cohort correlated with parents demanding obedience. In the 2011 cohort, high SES was associated with being allowed to show anger, parents demanding obedience, not being slapped, paternal strictness, the father being viewed as the respected authority, and with both parents being viewed as supportive, rather than mother or father only. Overall, most of the correlations and mean differences in Table 1 were low, and only a minority reached statistical significance. 
We ran the regression models, with and without controlling for age and education. The controls were added to partially account for the influence of income, because income, education, and age are related. However, because the estimates (i.e., regression coefficients, odd ratios, and significance levels) from the models without age and education did not differ from the regression estimates from the models controlling for age and education, we have reported only the models without these controls. We also ran the regression analyses using both the original and the recoded obedience demands and slapping variables, to insure that our recoding had not affected the results. The estimates (i.e., regression coefficients, odd ratios, and significance levels) seen in the analyses with the recoded variables were the same as those found in the regressions with the original variables.

\section{Time Trends in Authoritarian Parenting Practices}

Did parents' directive control and the distribution of parental roles in the family, as perceived by young to middle adults, change over the 50 years covered in this study? To answer this question, we used stepwise logistic regression models predicting the various indicators of directive control and distribution of roles in the family from cohort, gender, and the cohort by gender interactions. The results, which are shown in the first columns of Table 2 and Table 3 , suggest that the answer is yes, as all cohort effects were significant.

Directive control. We first tested whether there were any significant differences between cohorts in directive control by regressing each of the directive control measures on cohort (represented by the two effect codes). When the Chi-square tests were significant, meaning that inserting cohort as a predictor of directive control practices did improve the model, we proceeded with the post-hoc analyses in order to see between which cohorts did the differences in directive practices appear. Looking first at the regression results for demanding obedience, the 
Chi-square test was significant, $\chi_{(d f=2)}^{2}=169.64, \mathrm{p}<.001$. As shown in Table 2, probing using dummy coded cohort (2011 versus 1958) was significant, and suggested that the 2011 cohort participants were less likely to having experienced their parents' demanding obedience from them, compared to the participants from the 1958 cohort $(\mathrm{OR}=0.19)$. However, there were no significant differences in obedience demands between the participants from the 1958 cohort and the participants from the 1981 cohort. Post-hoc analyses showed also that the greatest drops were between reports in 1981 and 2011. Participants from the 2011 cohort were less likely to have experienced parents demanding obedience from them than the participants from the 1981 cohort $(\mathrm{OR}=0.15)$. Over 53 years, these differences translate into an $81 \%$ decrease in the probability that parents would demand obedience, and over 30 years this translates into $85 \%$ decrease in the probability of being demanded obedience by parents. The raw percentages are shown in Table 4. Whereas $66 \%$ of the 1958 cohort and $71 \%$ of the 1981 cohort reported their parents always demanded obedience from them, only $28 \%$ of participants in the 2011 cohort experienced the same.

Looking next at physical punishment (slapping), cohort differences were evident, $\chi_{(d f=2)}^{2}$ $=89.30, \mathrm{p}<.001$. Post-hoc probing showed that, over time, the 2011 cohort participants were less likely to report being slapped during childhood compared to the participants in the 1958 cohort $(\mathrm{OR}=0.07)$. There were no significant differences between participants from the 1958 cohort and those from the 1981 cohort in their reports on physical punishment. However, participants from the 2011 cohort were less likely to report they were slapped during childhood than the participants in the 1981 cohort $(\mathrm{OR}=0.08)$. This means there was a $93 \%$ decrease in the likelihood of being slapped by their parents over the 53 years studied, and a $92 \%$ decrease in the likelihood of being slapped over the 30 years between the last two cohorts. Table 4 shows 
that $20 \%$ and $18 \%$ of the adults in the 1958 and 1981 cohorts remembered that their parents had slapped them, whereas only $2 \%$ in the 2011 cohort remembered the same. It should be added that only a minority, $17 \%$ of the adults in the 1958 cohort, said their parents never had slapped them. By contrast, a majority in the 2011 cohort, $77 \%$ reported that their parents never had slapped them.

With respect to the participants' retrospective reports on parents' restrictions of expressing anger, the regression showed significant change across cohorts, $\chi_{(d f=2)}^{2}=176.42, \mathrm{p}<$ .001. Post-hoc analyses showed that, compared to the 1958 cohort, both 1981 and 2011 cohort participants differed in the way they recollected their parents allowing them to show anger. The 2011 participants were 8.8 times more likely to report they were allowed to show anger compared to the 1958 participants. In other words, the likelihood of having had parents who did not allow expressions of anger toward them decreased. However, the change went in the opposite direction when comparing the first two cohorts: participants from the 1981 cohort were 3 times more likely to report their parents did not allow them to show anger compared to the 1958 participants. As the post-hoc analyses also showed, the decreasing trend in the restriction of emotions found between the 1958 and the 2011 cohorts was also found between the last two cohorts. Participants from the 2011 cohort were 2.94 times more likely to have been allowed the expression of emotions by their parents compared to the 1981 cohort participants, meaning a 194\% increase in being allowed to show anger between 1981 and 2011. It can be seen in Table 4 that the greatest difference was between the 1981 and 2011 cohorts, from $72 \%$ participants in 1981 remembering they were not allowed to show anger, to only 11\% in 2011 reporting their parents restricted their expression of negative emotions. Overall, then, expressions of anger toward parents became more acceptable. 
Concerning parental strictness, this form of authoritarian behavior dropped significantly. For fathers' strictness, the results of the OLS regression models suggested that the participants from the 2011 cohort were less likely to report their father as strict, compared to participants from the 1981 cohort. In other words, the likelihood of fathers being very strict was reduced between 1981 and 2011. The time trend, then, was an overall reduction in fathers' strictness. As shown in Table 4, a majority (52\%) of the adults in the 1981 cohort, compared to a minority (17\%) of the cohort 2012 adults, viewed their fathers as strict.

With regard to mothers' strictness, similar trends were seen (see Table 2). Participants in 1981 were less likely than participants in the 1958 cohort to report their mothers as strict. This means there were substantial reductions from 1981 to 2011 in maternal strictness. As reported in Table 4, the percentage of adults who experienced their mothers as strict in the 1981 cohort (42\%) was almost four times higher than the percentage of adults in the 2011 cohort having experienced the same (11\%).

To summarize, in comparison to how young adults perceived their parents' directive control 30 to 50 years ago, the parents of young adults in 2011 were perceived as demanding less obedience, slapping their children less, allowing their children to express more anger toward them, and being less strict. These results show a clear decline in the use of directive control.

Distribution of roles and responsibilities in the family. We expected changes in the tendency for fathers to be seen as authoritarians and mothers as caregivers, toward viewing fathers as less authoritarian, sharing household decision-making, and both parents garnering respect from their children. As shown in Table 3, these expectations were largely confirmed.

Regarding household decisions, there were again significant differences across cohorts, $\chi_{(d f=4)}^{2}=113.02, \mathrm{p}<.001$. Post-hoc analyses showed that, compared to the 1958 participants, 
the 2011 cohort participants were 3.86 times more likely to report that their mothers, rather than fathers, made decisions in the households. Similarly, over the studied period, participants were 5.18 times more likely to report that both mothers and fathers made decisions in the household together, rather than fathers alone (see Table 3). In other words, there was an increase over time in the likelihood of mothers and both mothers and fathers making household decisions, rather than fathers alone, with slightly higher odds for both parents making decisions. Post-hoc analyses also showed this trend to be stronger between the last two cohorts, rather than between the first two. Participants from the 2011 cohort were 3.44 times more likely, and 6.42 times more likely to state that their mothers and, respectively both parents made decisions at home, compared to the 1981 cohort. The shifts away from fathers making most of the decisions to both mothers and fathers making household decisions can be seen in Table 4. The biggest changes can be seen in the decreasing percentage of people reporting fathers alone made decisions (e.g., from $77 \%$ in 1981 to $33 \%$ in 2011 ), and in the increasing percentage of people reporting both parents made decisions in the household (from 5\% in 1981 to $48 \%$ in 2011).

Regarding which parent was most respected, again there were significant differences across cohorts, $\chi_{(d f=4)}^{2}=225.95, \mathrm{p}<.001$. Post-hoc analyses showed that comparing fathers and both parents being respected, over the 53 years period participants were 10.27 times more likely to report both parents as being respected (see Table 3). This means there was a substantial increase over time in the likelihood that both parents would garner respect. There were no significant differences between the 1958 and 1981 cohort in which parent was most respected. Post-hoc analyses also showed these differences to prevail when comparing the 2011 cohort with the 1981 cohort $(\mathrm{OR}=20.49$ for both parents garnering respect). These results suggest that over time (see Table 4), participants shifted from primarily declaring they respected their fathers (44 
and $77 \%$ of the 1958 and 1981 cohort participants, versus only $14 \%$ of the 2012 cohort participants), to reporting they respected both their mothers and fathers (30 and $25 \%$ of the participants in the 1958 and 1981 cohorts versus $51 \%$ of the participants in the 2011 cohort).

The tests examining cohort differences in which parent was viewed as providing support were also significant, $\chi_{(d f=4)}^{2}=33.97, \mathrm{p}<.001$ (see Table 3). Post-hoc analyses showed that, when comparing fathers with both parents being viewed as supportive, participants from the 2011 cohort were 2.47 times more likely to report both parents as supportive, compared to participants from the 1958 cohort. Although there were no differences between the first two cohorts, post-hoc analyses showed participants from the 2011 cohort to be 5.05 times more likely to turn to both parents for support, compared to participants from the 1981 cohort. Overall, the percentages shifted, with increased numbers reporting that they turned to both parents when distressed. Nevertheless, mothers remained the parent viewed as most supportive. This can be seen clearly in Table 4 , where more than $60 \%$ of the people in each cohort viewed their mother as the parent providing support.

Because the first two cohorts were related to each other, we tested whether their nonindependence might have affected the results. By using a planned sampling, we extracted samples from the $1958(n=136,48 \%$ males $)$ and $1981(n=69,58 \%$ males $)$ cohorts making sure not include members from the same family over the two cohorts. Every third participant, by rotation, was selected. For the first cohort, gender also was used for stratification. We then repeated all the previous analyses using these samples, comparing the original to the new results. We found no significant differences in the directions of estimates or their levels of significance. We conclude that the dependencies between the first two cohorts did not significantly influence our results. 


\section{Gender Differences in Directive Control, Distribution of Parental Roles in the Family}

Given previous studies have shown that women and men tend to report differently on their parents' disciplining practices, with men reporting harsher parental treatments, we asked whether there were gender differences in reported parental directive control, and distribution of parental roles in the family. Therefore, we modeled the linear effects of cohort and gender on parental practices and parental roles. The results for the linear effects of gender are shown in Table 2 for directive control measures, and Table 3 for father as authoritarian figures, under the column headed Step 2, on the row labeled gender. In a third step, we also modeled the interaction between cohort and gender in order to see whether the gender differences in parental directive control and distribution of parental roles in the family are the same for all cohorts, or if they differ between cohorts.

Overall, we found gender effects for all the measures of distribution of parental roles in the family, but none for directive control. Compared with men, women were 1.60 times more likely to report that their mothers, rather than their fathers, made decisions. Similarly, regarding which parent was most respected, women were 1.45 times more likely than men to report that their mothers garnered their respect most. Moreover, for both the comparisons of father with mother and father with both parents being viewed as supportive, gender was a significant predictor. Women were 0.67 and 0.57 times as likely as men to report turning to their mothers or to both parents rather than turning to their fathers for support. This means that compared to men, women were more likely to ask their fathers, rather than their mothers or both parents for support. As these results show, men and women tended to answer rather differently on perceived maternal and paternal roles, irrespective of the cohort. In addition, the shift toward more egalitarian mothers' and fathers' roles was more evident in women's views than in men's, 
and these gender differences were found in all cohorts.

\section{DISCUSSION}

In this study we examined how authoritarian parenting practices based on control and the distribution of parents' roles in the family changed over the last 53 years in Sweden. The results reveal that some important changes have taken place in the way parents raise their children.

First, directive control has almost disappeared. In the last generation we examined, few of the adults sampled remembered being parented in a way that restricted their behavior or their feelings. Few reported being slapped with any regularity. By comparison, more than half of the young adults in the 1958 and 1981 cohorts remembered their parents as demanding obedience and constraining their emotions. In addition to dramatic declines in directive control, the genderstereotyped roles of yesterday's parents have also changed. In the 2011 cohort, young adults reported fathers and mothers shared authority. Although the 2011 cohort relied on their mothers almost as much as the young adults of the 1958 cohort, fathers were increasingly viewed as sources of support. These results are consistent with what has been found for shorter intervals of history (Campbell \& Gilmore, 2007, Jung \& Sterling Honig, 2000). Although other studies have shown decreases in punitive practices (Durrant et al., 2003, Straus, 2010) or changes in parenting roles (Ferri \& Smith, 2003), this study showed that both parenting practices based on punitive and directive control and the distribution of parenting roles changed simultaneously. Taken together, the evidence converges to suggest that contemporary parents are more flexible and democratic than parents in past generations.

Most of the changes in parents' use of directive control occurred between the time that the second and the third cohorts were parented - roughly from the mid-1950s to the beginning of the $21^{\text {st }}$ century. We expected the changes to be more continuous because there was extensive 
emphasis on equality and children's rights in Swedish society during this time (for a review, see Ahlberg, Roman, \& Duncan, 2008). There are three possible explanations, albeit post hoc, that come to mind. One is that the pattern is due to the first two cohorts being from the same family. We ruled this out, however, given that this is not typical of intergenerational studies, where significant differences have been found between parents and children in the way they raised their offspring (see Campbell \& Gilmore, 2007; Jung \& Sterling Honig, 2000). Another possibility is that the second cohort, directly affected by laws enacting bans on corporal punishment in 1979 (see Ahlberg, Roman, \& Duncan, 2008 for a review), interpreted their parents' behavior more harshly than the previous generation. A final possibility is that the reports of the second cohort are accurate, and that like many people who find their behaviors restricted, their parents encountered psychological reactance (i.e., strong negative feelings when choice is restricted, Brehm \& Brehm, 1981) and did not easily give up the right to discipline their children as they saw fit. Nonetheless, the overall picture suggests that authoritarian practices in Sweden have indeed declined.

Although we did not directly examine why these trends have occurred, there are several plausible explanations. Regarding drops in punitive and directive control, the enactment of laws banning corporal punishment and legislation ratifying and enforcing the Convention on the Rights of the Child are likely sources of changes in parenting in Sweden. In addition, there have been dramatic changes in education, with contemporary emphasis on providing free higher education to any resident who qualifies. In a similar manner, there have been legislation changes and changes in social attitudes that likely promote more democratic and egalitarian practices, including increases in maternal employment, laws promoting gender equality, laws and policies promoting joint care (e.g., liberal maternal and paternal maternity leaves), and emphasis on 
democracy at work, in the home, and in the school. Given the links between higher education and less harsh discipline (Simons, Whitbeck, Conger, \& Wu, 1991), between both parents' being employed and paternal involvement (Hofferth \& Goldscheider, 2010), and between policies promoting equality and fathers' involvement in childcare (Sarkadi, Kristiansson, Oberklaid, \& Bremberg, 2008), the changes in parenting practices and roles that were observed in this study make sense. An amalgamation of political, legal, economic, and social factors has opened the way for reducing authoritarian practices and creating the means for fathers to become more involved in their children's upbringing and for mothers to share power in the family. Although we cannot directly link the social changes occurring during the time that we have studied to declines in authoritarian practices based on directive control and gender-stereotyped roles, the changes in parenting are not surprising. They are, nonetheless, striking.

The differences between men's and women's reports in the current study were similar to those found previously (Starrels, 1994). Women were more likely than men to report that their mothers made household decisions and were most respected. In addition to these differences, women viewed their mothers as important household authorities. These findings are in line with the literature on differences in socialization due to child's gender. As previous studies have shown, mothers tended to be more sensitive towards daughters, than towards sons (Bornstein, Putnick, Heslington, Gini, Suwalsky, \& Venuti, 2008; Cassano \& Zeman, 2010). Also as shown previously, fathers allocate more time and financial rewards to sons, than to daughters (see Starrels, 1994). Thus, children see as household authority the parent they have a stronger relationship with, who offers instrumental support, or with whom they can identify (e.g., Starrels). Overall, the gender differences in adults' retrospective reports of parental roles found here converge with previous studies. 


\section{Limitations \& Strengths}

There are several limitations that should be considered. First, we used single-item measures of parenting practices, rather than the multi-item measures traditionally used to measure the authoritarian parenting style. We chose to use individual items, however, so that we could capture a finer picture of which practices have changed and to ensure the equivalence of measures across cohorts. By using the same questions, we ensured comparability between cohorts, but we still have to take into account that the meaning of words might have changed over time. Second, the reports were retrospective. We examined whether factors influencing attitudes may reveal biases evident in retrospective reports. It might be, for example, that retrospective reports reflect current attitudes more than actual parenting behaviors. Prior comparison of the 1981 cohort's reports of their parents' behaviors with the 1958 cohort's selfreports established the validity of the retrospective reports on parents' discipline behaviors (Stattin et al., 1995), providing some confidence that the reports are informed by actual parenting behaviors. The question remains, though, whether the changes in laws and societal views on discipline practices influenced reports through affecting participants' attitudes. The reports from the 1981 cohort coincide with these changes; laws enacted in the 1950s and 60s went into effect when they were being parented. There is no evidence, however, that they under-reported their parents' behavior, as they reported harsher parenting than their parents. It might be that awareness of the laws increased reporting, but one would think this would also be true of the 2011 cohort, who also experienced societal pressure to recognize the rights of children. If this is the case, then we can conclude that both the latter cohorts reported more in comparison to the first cohort. This does not, however, negate an overall trend toward less authoritarian practices. Given the young age of the second cohort, and the first two cohorts being related, readers might 
also think that differences in the reports could be artifacts of the design and cohort composition. We ruled these out, through analysis controlling age and education, as well as target analysis examining whether the dependencies in the first two cohorts shaped the results. Still, we are confident that the overall drop in authoritarian parenting practices and parental roles hold, representing important social change.

Other issues that we were not able to fully address include questions about the generalizability of these findings. Due to the composition of the first two cohorts, we had to exclude participants born outside of the Nordic countries. Although the Nordic countries have distinct cultural practices, it is not unreasonable to think that similar changes could occur in similar cultures if the same social, economic, legal, and political changes have occurred. The available evidence suggests that, at least in some aspects, such as harsh discipline, they may be quite generalizable to other Western countries. Other studies (Bussmann et al., in press; Durrant et al., 2003; Straus, 2010) have found decreased support for physical punishment in Sweden, and similar results have emerged in other countries that have laws against physical punishment, but also in countries that have not legally banned physical punishment (Bussmann et al., in press). Therefore, this seems to be a trend in Western society, and not just a localized event. Other potential moderating conditions also need to be addressed. We were not able to directly examine whether birth order or family type (e.g., biological, step-parent, reconstituted family, samegender parents, etc.) affected the results. These potential moderators await testing in countries with similar cultural and social change conditions.

Our study also had some important strengths. These include a long span of time (over half a century), multiple indicators of the control dimension of authoritarian parenting, community samples, and large sample sizes in all three cohorts. We used the same measures for 
all three cohorts, which is an aspect rarely encountered in previous research. Due to the long span of the study, we were able to cover a period of time with fundamental legislative changes regarding family life and parenting. Our focus on authoritarian parenting practices was strategic, given the legislation aimed at reducing them and research suggesting that parenting practices, as opposed to styles, are more sensitive to social influence (Darling \& Steinberg, 1993).

\section{Implications for practice}

The results of this study showed a strong decrease in the authoritarian parenting practices that are most often associated with negative developmental outcomes. One might ask how youth mental health and problem behavior have changed during the same time. Studies on trends in the mental health of youth found that internalizing and externalizing problems have risen in the recent decades (e.g., Collishaw, Goodman, Pickles, \& Maughan, 2007). One might think these trends are inconsistent with our findings. In our opinion the lack of corresponding increases in children's adjustment does not cancel the positive effects the change in parenting brings to children. We argue quite to the contrary, as other changes are likely to be responsible for increases in reported problems, such as increased sensitivity to and recognition of emotional problems, as well as more resources, awareness, and knowledge in detecting mental health problems. In light of these other changes, it is still reasonable to suggest that practitioners should be apprised of these changes, as recent generations seem to have greater parenting resources than past generations, in that families seem to be more democratic and flexible, with higher levels of education, and with an increased involvement from fathers. These resources are social capital that can be used to offset social changes that might be responsible for children's and adolescents' problems.

Conclusions and Future Directions 
This study provided evidence that the trends in authoritarian parenting practices and parents' roles seen in studies of shorter periods of time hold for longer periods of time. Authoritarian parenting in Sweden is on the decline. The next step is to determine how these changes are linked to children's health and well-being over time. It will also be important to determine in what ways other parenting practices have changed and to determine the best way to support optimal parenting. The current picture of declines in harsh and punitive parenting, as well as in gender-stereotypes parenting roles, suggests that there is room for optimism. 


\section{REFERENCES}

Ahlberg, J., Roman, C., Duncan, S. (2008). Actualizing the "democratic family"? Swedish policy rhetoric versus family. Social Politics 15, 79-100. doi: 10.1093/sp/jxn003

Alwin, D.F. (1997). Parental socialization in historical perspective. In C. D. Ryff \& M. Mailick Seltzer (Eds.), The parental experience in midlife (pp. 105 - 167). Chicago: The University of Chicago Press.

Amato, F. R. \& Fowler, F. (2002). Parenting practices, child adjustment, and family diversity. Journal of Marriage and Family, 64, 703-716. doi: 10.1111/j.1741-3737.2002.00703.x

Baldwin, A.L. (1948). Socialization and the parent-child relationship. Child Development, 19, 127-136. Retrieved from: http://www.jstor.org/stable/1125710

Baumrind, D. (1966). Effects of authoritative parental control on child behavior. Child Development, 37, 887-907. Retrieved from: http://www.jstor.org/stable/1126611

Baumrind, D. (1991). The influence of parenting style on adolescent competence and substance use. Journal of Early Adolescence, 11, 56-95. doi: 10.1177/0272431691111004

Bornstein, M. H., Putnick, D. L., Heslington, M., Gini, M., Suwalsky, J. T. D., \& Venuti, P. (2008). Mother-child emotional availability in ecological perspective: Three countries, two regions, two genders. Developmental Psychology, 44, 666-680. doi: 10.1037/00121649.44.3.666

Brehm, S. S., \& Brehm, J.W. (1981). Psychological reactance: A theory of freedom and control. New York: Academic Press.

Brenner, V., \& Fox, R. A. (1999). An Empirically Derived Classification of Parenting Practices. Journal Of Genetic Psychology, 160, 343. doi: 10.1080/00221329909595404

Bronfenbrenner, U. (1986). Ecology of the family as a context for human development: Research 
perspectives. Developmental Psychology, 22, 723-742. doi: 10.1037/0012-1649.22.6.723

Bussmann, K.-D., Erthal, C., \& Schroth, A. (in press). The effect of banning corporal punishment in Europe: A five-nation comparison. In J. Durrant, \& A. B. Smith (Eds.), A safer world for children: Global progress towards ending physical punishment. London: Sage.

Campbell, J. \& Gilmore, L. (2007). Intergenerational continuities and discontinuities in parenting styles. Australian Journal of Psychology, 59, 140-150. doi: 10.1080/00049530701449471

Cassano, M. C., \& Zeman, J. L. (2010). Parental socialization of sadness regulation in middle childhood: The role of expectations and gender. Developmental Psychology, 46, 12141226. doi: $10.1037 / \mathrm{a} 0019851$

Cohen, J. \& Cohen, P. (1983). Applied multiple regression/correlation analysis for the behavioral sciences. Hillsdale, N.J: L. Erlbaum Associates.

Collishaw, S., Goodman, R., Pickles, A., \& Maughan, B. (2007). Modelling the contribution of changes in family life to time trends in adolescent conduct problems. Social Science \& Medicine, 65, 2576-2587. doi: 10.1016/j.socscimed.2007.06.010

Conrade, G., \& Ho, R. (2001). Differential parenting styles for fathers and mothers: Differential treatment for sons and daughters. Australian Journal of Psychology, 53, 29-35. Retrieved from: http://onlinelibrary.wiley.com/doi/10.1080/00049530108255119/pdf

Dallaire, D. H., Pineda, A. Q., Cole, D. A., Ciesla, J. A., Jacquez, F., LaGrange, B., \& Bruce, A. E. (2006). Relation of positive and negative parenting to children's depressive symptoms. Journal of Clinical Child and Adolescent Psychology, 35, 313 - 322. doi: $10.1207 / \mathrm{s} 15374424 \mathrm{jccp} 3502 \_15$

Darling, N. \& Steinberg, L. (1993). Parenting style as context: An integrative model. Psychological Bulletin, 113, 487-496. doi: 10.1037/0033-2909.113.3.487 
Durrant, J. E., Rose-Krasnor, L., \& Broberg, A. G. (2003). Physical punishment and maternal beliefs in Sweden and Canada. Journal of Comparative Family Studies, 34, 586-604. Retrieved from: http://search.ebscohost.com/login.aspx?direct $=$ true $\& \mathrm{db}=\mathrm{afh} \&$ $\mathrm{AN}=10904497 \&$ site $=$ ehost-live

Ferri, E. \& Smith, K. (2003). Family life. In E. Ferri, J. Bynner \& M. Wadsworth (Eds.), Changing Britain, changing lives (pp. 140-147). London: Institute of Education.

Gadlin, H. (1978). Child discipline and the pursuit of the self: an historical interpretation. In H. W. Reese \& L. P. Lipsitt (Eds.), Advances in child development and behaviour (Vol. 12, pp. 231-261). New York: Academic Press.

Graffar, M. \& Corbier, J. (1972). Contribution to the study of the influence of socio-economic conditions on the growth and development of the child. Early Child Development and Care, 1, 141-179. doi:10.1080/0300443720010201

Hofferth, S. \& Goldscheider, F. (2010). Does change in young men's employment influence fathering? Family Relations, 59, 479-493. doi: 10.1111/j.1741-3729.2010.00617.x

Hosley, C. A., \& Montemayor, R. (1997). Fathers and adolescents. The role of the father in child development. In M. E. Lamb (Ed), The role of the father in child development (3rd ed.) (pp. 162-178). Hoboken, NJ: John Wiley \& Sons.

Jung, K. \& Sterling Honig, A. (2000). Intergenerational comparisons of paternal Korean child rearing practices and attitudes. Early Child Development and Care, 165, 59-84. doi: $10.1080 / 0300443001650105$

Karlberg, P., Klackenberg, G., Klackenberg-Larsson, I., Lichtenstein, H., Stensson, J., \& Svennberg, I. (1968). The development of children in a Swedish urban community. A prospective longitudinal study - I. Introduction, design and aims of the study. Description 
of the sample. Acta Paediatrica, 57(Issue Supplement S187), 9-28. doi: 10.1111/j.16512227.1968.tb06039.x

Klackenberg, G., Karlberg, P., Klackenberg-Larsson, I., Lichtenstein, H., Stensson, J., \& Svennberg, I. (1968). The development of children in a Swedish urban community. A prospective longitudinal study - II. The social background and its changes during the children's first three years of life. Acta Paediatrica, 57(Issue Supplement S187), 28-47. doi: 10.1111/j.1651-2227.1968.tb06040.x

Lewis, C. C. (1981). The effects of parental firm control: A reinterpretation of findings. Psychological Bulletin, 90, 547-563. doi: 10.1037/0033-2909.90.3.547

Maccoby, E. E., \& Martin, J. A. (1983). Socialization in the context of the family: Parent-child interaction. In P. H. Mussen (Series Ed.) \& E. M. Hetherington (Vol. Ed.), Handbook of child psychology: Vol. 4. Socialization, personality, and social development (4th ed., pp. 1-101). New York, NY: Wiley.

Michael, S. (1987). Are sons and daughters treated more differently by fathers than by mothers? Developmental Review, 7, 183-209. doi: 10.1016/0273-2297(87)90012-8

Nelson, L., Padilla-Walker, L., Christensen, K., Evans, C., \& Carroll, J. (2011). Parenting in emerging adulthood: an examination of parenting clusters and correlates. Journal of Youth and Adolescence, 40, 730-743. doi: 10.1007/s10964-010-9584-8

Nuffield Foundation (2009). Time trends in parenting and outcomes for young people. London, Nuffield Foundation. Retrieved from: http://www.nuffieldfoundation.org/publicationsand-resources

Oppenheimer, L. (2004). Perception of individualism in Dutch society: a developmental approach. International Journal of Behavioral Development, 28, 336-346. doi: 
$10.1080 / 01650250444000009$

Pampel, F. C. (2000). Logistic regression: A primer. Thousand Oaks, CA: Sage Publications.

Pedhazur, E.J. (1997). Multiple regression in behavioral research: Explanation and prediction. South Melbourne, Vic.: Wadsworth/Thomson Learning.

Robinson, C. C., Mandelco, B., Frost Olsen, S., \& Hart, C. H. (1995). Authoritative, authoritarian, and permissive parenting practices: development of a new measure. Psychological Reports, 77, 819-830. doi: 10.2466/pr0.1995.77.3.819

Russell, A., Aloa, V., Feder, T., Glover, A., Miller, H., \& Palmer, G. (1998). Sex-based differences in parenting styles in a sample with preschool children. Australian Journal of Psychology, 50, 89-99. doi: 10.1080/00049539808257539

Sarkadi, A., Kristiansson, R., Oberklaid, F., \& Bremberg, S. (2008). Fathers' involvement and children's developmental outcomes: a systematic review of longitudinal studies. Acta Paediatrica, 97, 153-158. doi: 10.1111/j.1651-2227.2007.00572.x

Schaefer, E. S. \& Bell, R. Q. (1958). Development of a parental attitude research instrument. Child Development, 29, 339-361. Retrieved from: http://www.jstor.org/stable/1126348

Schofer, E. \& Meyer, J.W. (2005). The worldwide expansion of higher education in the twentieth century. American Sociological Review, 70, 898-920. doi: 10.1177/000312240507000602

Scott, J., Collishaw, S., Gardner, F., \& Maughan, B. (2009). Can changes in parenting explain the rise UK adolescent problem behaviour? Annual Meeting of the American Sociological Association. San Francisco, CA: American Sociological Association.

Simons, R. L., Whitbeck, L. B., Conger, R. D., \& Wu, C. (1991). Intergenerational transmission of harsh parenting. Developmental Psychology, 27, 159-171. doi: 10.1037/00121649.27.1.159 
Starrels, M. E. (1994). Gender differences in parent-child relations. Journal of Family Issues, 1, 148-165. doi: 10.1177/019251394015001007

Statistics Sweden (2010):

http://www.ssd.scb.se/databaser/makro/MainTable.asp?yp=qmnggr\&xu= 91506001\&omradekod=NR\&omradetext=National+accounts\&lang=2\&langdb=2

Statistics Sweden (1960):

http://www.scb.se/Grupp/Hitta_statistik/Historisk_statistik/_Dokument/Statistisk\%20\%C 3\%A5rsbok\%201914-2001/Statistisk\%20arsbok\%20for\%20Sverige\%201960.pdf

Stattin, H., Janson, H., Klackenberg-Larsson, I., \& Magnusson, D. (1995). Corporal punishment in everyday life: An intergenerational perspective. In J. McCord (Ed.), Coercion and punishment in long-term perspectives (pp. 315-347). New York, NY: Cambridge University Press.

Straus, M. A. (2010). Prevalence, societal causes, and trends in corporal punishment by parents in world perspective. Law and Contemporary Problems, 73(2), 1-30. Retrieved from: http://www.law.duke.edu/journals/lcp.

Straus, M. A. \& Paschall, M. J. (2009). Corporal punishment by mothers and development of children's cognitive ability: A longitudinal study of two nationally representative age cohorts. Journal of Aggression Maltreatment and Trauma, 18, 459-483. doi: $10.1080 / 10926770903035168$

Thornberry, T. P., Freeman-Gallant, A., Lizotte, A.J., Krohn, M.D., \& Smith, C.A. (2003). Linked lives: The intergenerational transmission of antisocial behavior. Journal of Abnormal Child Psychology, 31, 171-184. doi: 10.1023/A:1022574208366

United Nations: http://treaties.un.org/Pages/ViewDetails.aspx?src= TREATY\&mtdsg_no=IV- 
$11 \&$ chapter $=4 \&$ lang $=$ en

Zolotor, A. J., Theodore, A. D., Runyan, D.K., Chang, J.J., \& Laskey, A.L. (2011). Corporal

punishment and physical abuse: population-based trends for three-to-11-year-old children in the United States. Child Abuse Review, 20, 57-66. doi: 10.1002/car.1128 
Table 1

Correlations between age, education, SES and the measures of the retrospective parental behaviour (Spearman's rho) and mean differences in socio-demographics for parental roles during childhood (ANOVA).

\begin{tabular}{|c|c|c|c|c|c|c|c|}
\hline \multirow[b]{3}{*}{ Directive Control } & \multicolumn{3}{|c|}{$\begin{array}{c}1958 \text { cohort } \\
(n=385)\end{array}$} & \multicolumn{4}{|c|}{$\begin{array}{c}2011 \text { cohort } \\
(n=457)\end{array}$} \\
\hline & Age & Education & $\begin{array}{c}\text { Social class } \\
\text { (Graffar) }\end{array}$ & Age & Education & \multicolumn{2}{|c|}{ SES } \\
\hline & & & & & & & \\
\hline Demanding obedience & $.16 * * *$ & .02 & $-.10 *$ & .08 & .07 & .12 & $*$ \\
\hline Slapping & -.03 & -.07 & .06 & .03 & -.05 & -.11 & $*$ \\
\hline Not allowed show anger & -.09 & .04 & .02 & -.05 & .05 & -.16 & $* *$ \\
\hline Maternal strictness & & & & $.12 *$ & .02 & .04 & \\
\hline Paternal strictness & & & & $.13 * * *$ & .09 & .15 & $* *$ \\
\hline \multicolumn{8}{|l|}{ Fathers as authoritarian figures } \\
\hline Made household decisions & * & & & & & & \\
\hline Mother & 31.58 & 0.03 & -0.04 & 36.00 & -0.01 & -0.04 & \\
\hline Equal & 31.24 & -0.12 & 0.10 & 36.69 & 0.03 & 0.06 & \\
\hline Father & 33.07 & 0.08 & -0.07 & 37.66 & -0.07 & -0.11 & \\
\hline Respected & & & & & & & $*$ \\
\hline Mother & 31.11 & -0.01 & 0.06 & 36.10 & -0.19 & -0.17 & $\mathrm{a}$ \\
\hline Equal & 32.14 & -0.24 & 0.21 & 36.31 & 0.06 & -0.06 & $\mathrm{ab}$ \\
\hline Father & 32.55 & 0.06 & -0.07 & 37.15 & -0.01 & 0.18 & $\mathrm{~b}$ \\
\hline Supported child & & & & & $*$ & & $*$ \\
\hline Mother & 32.65 & 0.00 & -0.03 & 36.30 & $-0.09^{\mathrm{a}}$ & -0.09 & a \\
\hline Both & 31.24 & 0.05 & -0.10 & 37.09 & $0.16^{\mathrm{a}}$ & 0.22 & $\mathrm{~b}$ \\
\hline
\end{tabular}




\begin{tabular}{lllllll}
\hline Father & 34.10 & -0.13 & 0.12 & 37.47 & 0.11 & $0.13^{\text {ab }}$ \\
\hline
\end{tabular}

Note: All the Likert-type measures are coded from the lowest to the highest level. For the relationship between the socio-demographic variables and fathers as authoritarian figures measures we used ANOVA tests. In these analyses the values for education and SES were standardized, to ease interpretation.

$* p<.05 . * * p<.01 . * * * p<.001$. 
Table 2

Slopes (Standard Errors) from Logistic and OLS Regression Models Predicting Directive Control from Cohort and Gender

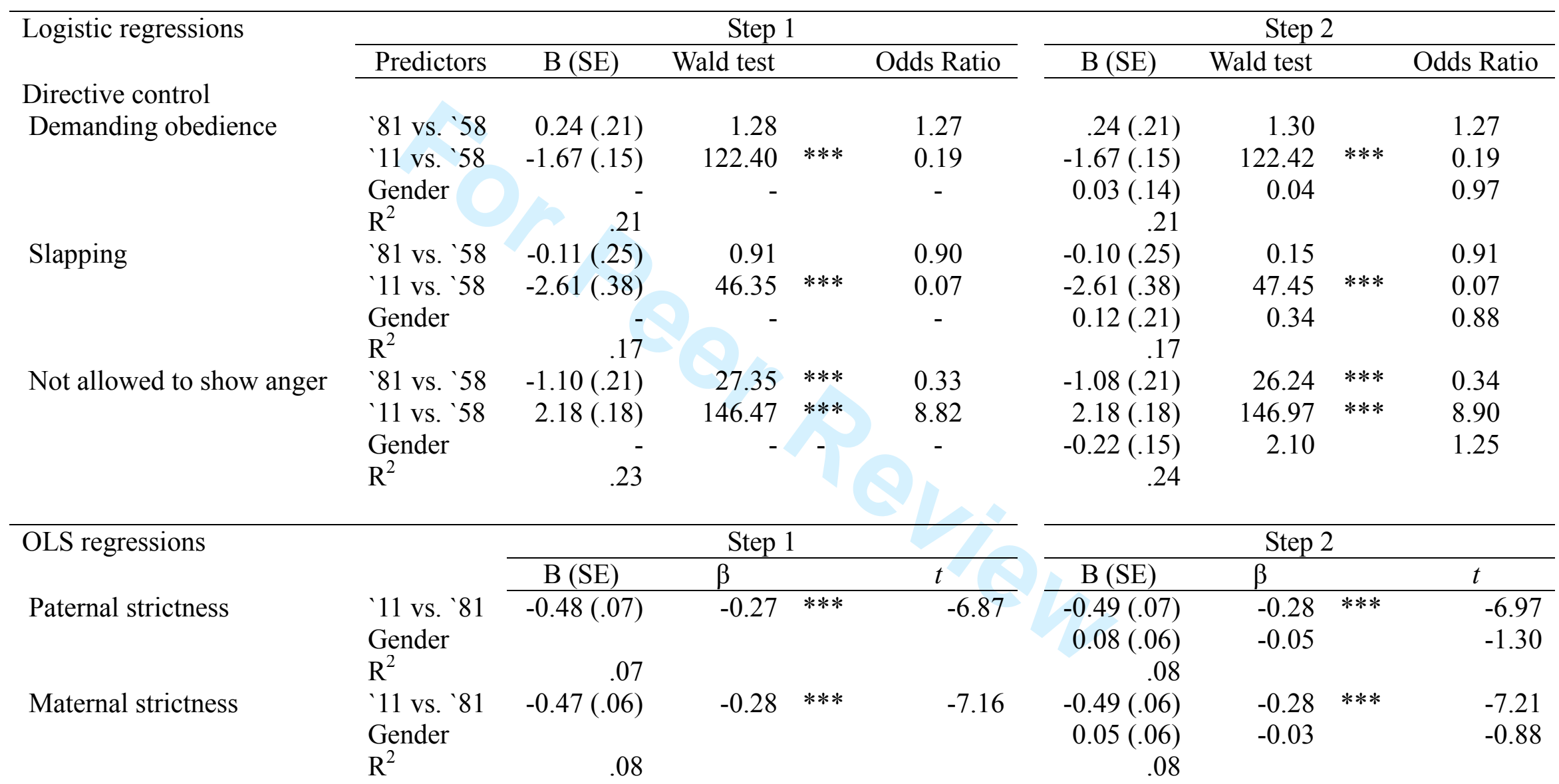

Note: Samples sizes were 836 to 991 for analyses with reports for both parents' practices. A significant level for the odds-ratios

means the value 1 is not included in the confidence interval. For the nominal regressions, Pseudo $R^{2}$ using Nagelkerke's formula is

provided for the full models. Men are the comparison group for gender 


\section{Page 41 of 44}

Journal of Marriage and Family

$* p<.05 . * * p<.01 . * * * p<.001$ 
Table 3

Slopes (Standard Errors) from Nominal Regression Models Predicting Fathers as Authoritarian Figures from Cohort and Gender

\begin{tabular}{|c|c|c|c|c|c|c|c|c|c|}
\hline \multirow{3}{*}{$\begin{array}{l}\text { Fathers as authoritari } \\
\text { figures }\end{array}$} & \multirow[b]{2}{*}{ Predictors } & \multicolumn{4}{|c|}{ Step 1} & \multicolumn{4}{|c|}{ Step 2} \\
\hline & & $\mathrm{B}(\mathrm{SE})$ & $\begin{array}{c}\text { Wald } \\
\text { test }\end{array}$ & & \multirow[t]{2}{*}{$\begin{array}{l}\text { Odds } \\
\text { Ratio }\end{array}$} & $\mathrm{B}(\mathrm{SE})$ & \multicolumn{2}{|l|}{$\begin{array}{l}\text { Wald } \\
\text { test }\end{array}$} & \multirow[t]{2}{*}{$\begin{array}{l}\text { Odds } \\
\text { Ratio } \\
\end{array}$} \\
\hline & \multicolumn{7}{|c|}{ Made household decisions } & & \\
\hline \multirow[t]{3}{*}{ Father vs. Mother } & $' 81$ vs. ${ }^{`} 58$ & $0.11(.23)$ & 0.25 & & 1.12 & $0.16(.23)$ & 0.46 & & 1.17 \\
\hline & `11 vs. `58 & $1.35(.19)$ & 48.64 & $* * *$ & 3.86 & $1.35(.19)$ & 48.03 & $* * *$ & 3.85 \\
\hline & Gender & - & - & & - & $0.47(.17)$ & 7.63 & $* *$ & 0.62 \\
\hline \multirow[t]{3}{*}{ Father vs. Equal } & ${ }^{\prime} 81$ vs. ${ }^{\prime} 58$ & $-0.21(.24)$ & 0.81 & & 0.86 & $-0.20(.24)$ & 0.71 & & 0.82 \\
\hline & `11 vs. `58 & $1.64(.18)$ & 78.74 & $* * *$ & 5.18 & $1.64(.18)$ & 78.57 & $* * *$ & 5.17 \\
\hline & $\begin{array}{l}\text { Gender } \\
\mathrm{R}^{2}\end{array}$ & .12 & - & & - & $\begin{array}{r}0.14(.16) \\
.13\end{array}$ & 0.79 & & 0.86 \\
\hline \multicolumn{10}{|l|}{ Respected } \\
\hline \multirow[t]{3}{*}{ Father vs. Mother } & '81 vs. `58 & $-0.42(.25)$ & 2.88 & & 0.66 & $-0.38(.25)$ & 2.38 & & 0.68 \\
\hline & `11 vs. `58 & $0.38(.18)$ & 4.37 & & 1.47 & $0.37(.18)$ & 4.12 & $*$ & 1.45 \\
\hline & Gender & - & - & & - & $0.42(.17)$ & 6.20 & $*$ & 0.65 \\
\hline \multirow[t]{4}{*}{ Father vs. Equal } & '81 vs. `58 & $-0.69(.41)$ & 2.87 & & 0.50 & $-0.68(.41)$ & 2.81 & & 0.50 \\
\hline & `11 vs. '58 & $2.33(.21)$ & 124.29 & $* * *$ & 10.27 & $2.33(.21)$ & 124.06 & $* * *$ & 10.25 \\
\hline & Gender & - & - & & - & $0.07(.17)$ & 0.18 & & 0.93 \\
\hline & $\mathrm{R}^{2}$ & .24 & & & & .25 & & & \\
\hline \multicolumn{10}{|l|}{ Supported child } \\
\hline \multirow[t]{3}{*}{ Father vs. Mother } & ${ }^{\prime} 81$ vs. $` 58$ & $0.02(.26)$ & 0.01 & & 0.93 & $-0.01(.26)$ & 0.00 & & 0.96 \\
\hline & `11 vs. '58 & $0.31(.21)$ & 2.20 & & 1.34 & $0.32(.21)$ & 2.35 & & 1.38 \\
\hline & Gender & - & - & & - & $-0.39(.19)$ & 4.08 & $*$ & 1.45 \\
\hline \multirow[t]{4}{*}{ Father vs. Both } & ${ }^{\prime} 81$ vs. '58 & $-0.71(.38)$ & 3.44 & & 0.49 & $-0.76(.38)$ & 3.90 & $*$ & 0.46 \\
\hline & `11 vs. `58 & $0.96(.25)$ & 13.25 & $* * *$ & 2.47 & $0.92(.25)$ & 13.63 & $* * *$ & 2.51 \\
\hline & Gender & - & - & & - & $-0.55(.23)$ & 5.79 & $*$ & 1.74 \\
\hline & $\mathrm{R}^{2}$ & .04 & & & & .05 & & & \\
\hline
\end{tabular}


Note: Samples sizes were 836 to 991 for analyses with reports for both parents' practices. A significant level for the odds-ratios means the value 1 is not included in the confidence interval. For the nominal regressions, Pseudo $R^{2}$ using Nagelkerke's formula is provided for the full models. Men are the comparison group for gender.

$* p<.05 . * * p<.01 . * * * p<.001$. 
Table 4

Parental practices and Parental roles as a Percentage of the Sample

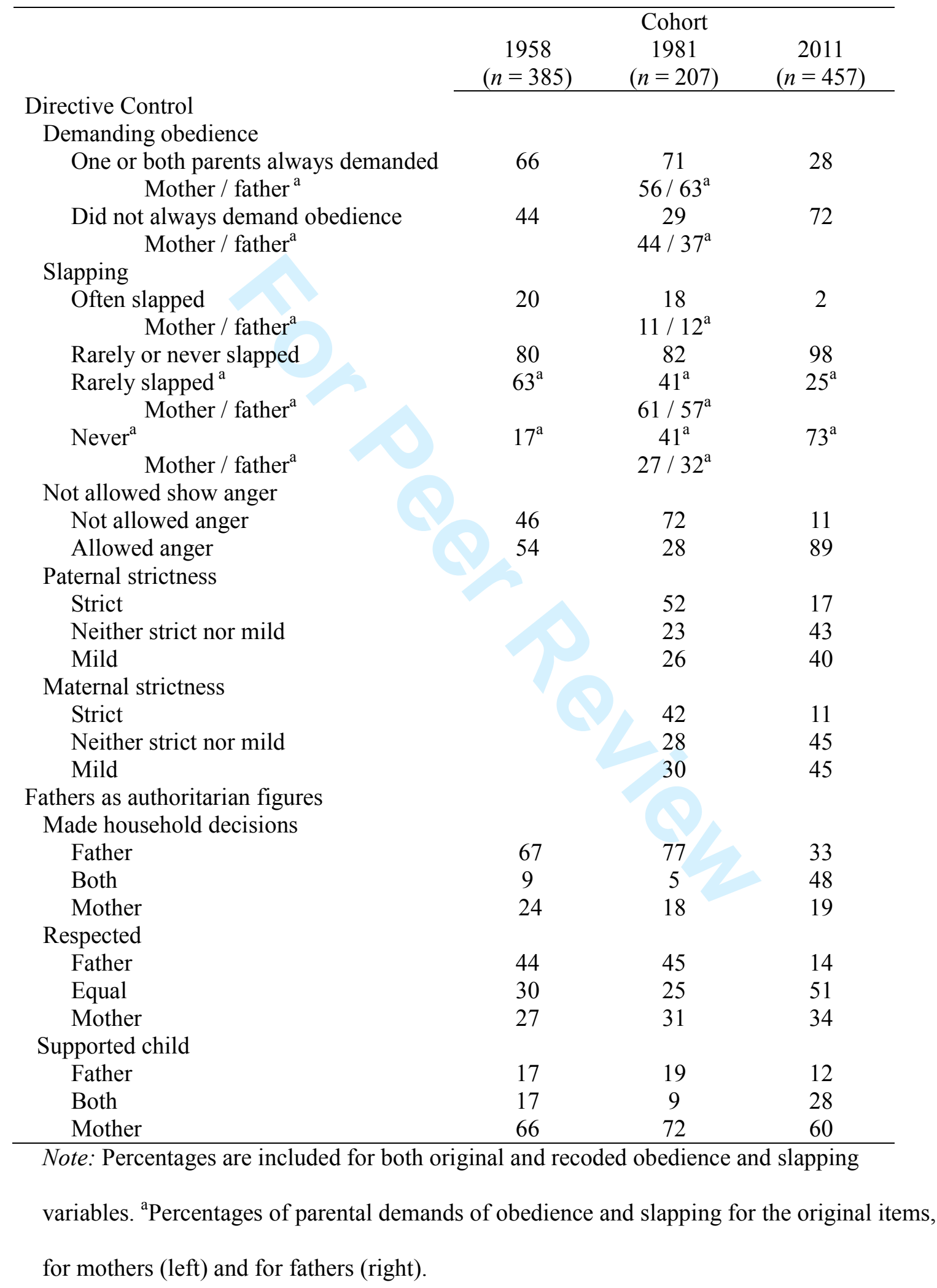

